\title{
New pedotransfer function ("CRC") for the prediction of unsaturated soil hydraulic conductivity using soil water retention data
}

\author{
Klaus Bohne ${ }^{1}$, Manfred Renger ${ }^{2}$, and Gerd Wessolek ${ }^{3 *}$ \\ ${ }^{1}$ Universität Rostock, Institute of Soil Science, Justus-von-Liebig-Weg 6, 18051 Rostock, Germany \\ ${ }^{2}$ Technische Universität Berlin, Institute of Ecology, Ernst-Reuter-Platz 1. 10587 Berlin, Germany \\ ${ }^{3}$ Institut für Ökologie, Technische Universität Berlin, Ernst-Reuter-Platz 1, 10587, Germany
}

Received November 28, 2018; accepted October 9, 2019

\begin{abstract}
Several review articles have emphasized, that a comprehensive set of pedotransfer functions may be applied throughout a wide range of disciplines of Earth system sciences and are of great importance for land surface models. Most pedotransfer functions deducing soil hydraulic data from nonhydraulic soil data such as soil texture and bulk density, yield soil water retention predictions, but do not provide information concerning soil hydraulic conductivity. For this reason, a simple method was developed to estimate soil hydraulic conductivity using soil water retention information. Empirical equations are established to predict soil hydraulic conductivity from soil water retention information. These equations are relatively straightforward and do not require the fitting of nonlinear functions. Predictions of soil hydraulic conductivity using 106 soil samples indicates the reliable performance of the new method. The prediction quality of the new method was estimated from the calibration data set, which produced equivalent results to the Zacharias and Wessolek pedotransfer function, which were even better than the predictions obtained from the original Mualem-van Genuchten model, the Soto fractal model, and the pedotransfer function reported by Weynants and Vereecken. The stochastic structure of the calibration data reflects the presence of important soil structural properties, which are not represented by the soil water retention characteristics.

Keywords: soil texture, hydraulic conductivity, transfer function, soil water retention
\end{abstract}

\section{INTRODUCTION}

Pedotransfer functions (PTF) are widely used to estimate soil hydraulic properties from soil texture and other basic soil properties. A comprehensive overview conducted by Minasny et al. (2017) has shown, that most of the PTFs being used in vadose zone research predict the soil water retention characteristics (WRC) from textural data. In a se-

\footnotetext{
*Corresponding author e-mail: gerd.wessolek@tu-berlin.de
}

cond step, some models can be used to estimate the soil hydraulic conductivity function from calculated soil water retention data. This procedure is often combined into an integrated approach (van Genuchten, 1980). Since hydraulic conductivity depends on both pore geometry and soil water content, there is an error propagation from water retention to hydraulic conductivity estimation yielding more or less large prediction errors.

Weynants et al. (2008), analysed 136 soil data sets obtained by steady-state downward flux and evaporation methods and predicted soil hydraulic conductivity $(K)$ with a root mean square error of $R M S E=0.318 \log _{10}(K)$ when using the Mualem-van Genuchten $(\mathrm{MvG})$ relationship and an $R M S E=0.306$ in the case of the Mualem-Ippisch model. These values hold for the prediction of hydraulic conductivity from soil water retention data. The PTF developed with their data set yielded an $R M S E=0.46$. The results obtained by two different PTFs including the ROSETTA software yielded far worse results. Puhlmann and Wilpert (2012) performed 795 multistep-outflow experiments on $100 \mathrm{~cm}^{3}$ soil cores and generated a PTF yielding an RMSE of between 0.6 and about $1.5 \log (K)$ for the calibration data set. This was somewhat better than the results of Wösten et al. (1999) obtained with his validation data set. With regard to the usage of concepts in land surface models, the RMSE values mentioned are not very satisfactory.

This contribution presents a new method to predict the hydraulic conductivity at specified values of the pore water pressure head, i.e. it directly links soil water retention and its hydraulic conductivity ("CRC" method). In its basic form it does not derive the parameters of a soil hydraulic

(C) 2019 Institute of Agrophysics, Polish Academy of Sciences 
model from non-hydraulic soil properties. Instead, it uses a few measured nodes of the water retention function to directly calculate the hydraulic conductivity at these points. Please note that the method requires measured water content data instead of textural data. However, we did not validate the method with a second data set. For comparison, two continuous models of soil water retention and two known pedotransfer functions were applied to the same data set. These are:

- the van Genuchten (1980) function fitted to water retention data followed by the Mualem evaluation of unsaturated conductivity at selected suction head points;

- a newly proposed fractal-based model (Soto et al., 2017) which provides predictions of hydraulic conductivity based upon water retention data;

- the pedotransfer functions after (i) Vereecken (Weynants et al., 2008) and (ii) after Zacharias and Wessolek (2007), which both predict the parameters of the van Genuchten/ Mualem model from non-hydraulic soil data.

The database used consists of 106 mineral soils from Germany and Austria with measured water retention and hydraulic conductivity data (Fig. 1). The data set has already been used in a previous study (Renger et al., 1999, 2014). Although the data originate from different sources (Feichtinger, 1990, Wendroth and Nielsen, 1995, Renger et al., 1999), for water retention, vacuum and pressure plate equipment were used, while hydraulic conductivity was measured by different versions of the evaporation method (Peters and Durner, 2008). The size of the soil cores varied between 100 and $250 \mathrm{~cm}^{3}$. Since the database contained only a few complete data sets of clay soils, this texture group was excluded from the evaluation.

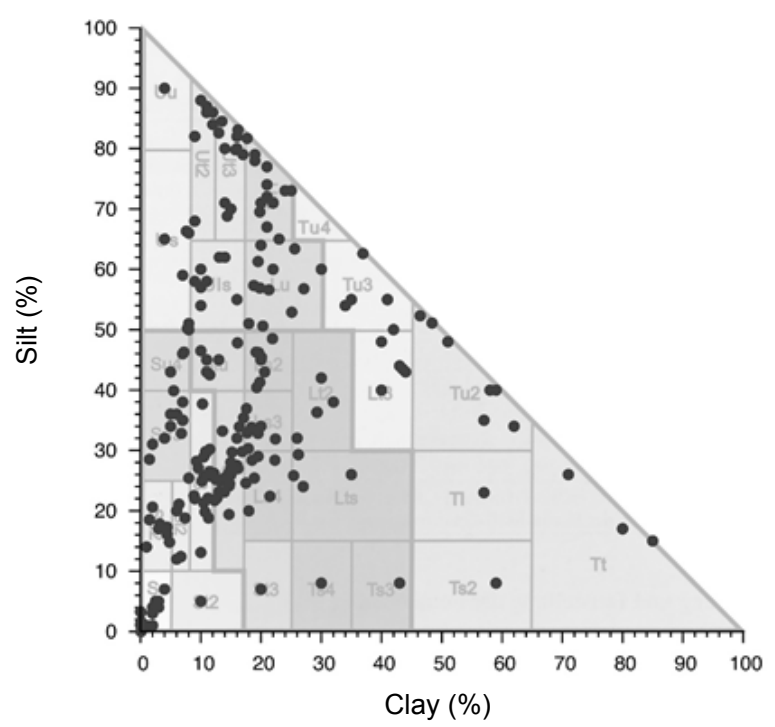

Fig. 1. Clay and silt content of the soil samples used. Due to missing values, soils with a clay content above $25 \%$ were excluded from the investigation of prediction errors.

\section{METHODS}

An earlier version of the CRC method was described by Renger et al. $(1999,2014)$. It was an autocorrelation procedure, which was subject to severe error propagation.

The new version described here avoids this drawback and yields stable parameters. In order to execute the method, the soil water content at $|h|=0,32,63,316$ and $15850 \mathrm{hPa}$ have to be known. Then, soil hydraulic conductivity at $|h|=32,63,100,300$ and $600 \mathrm{hPa}$ may be calculated.

Firstly, the soil under consideration has to be assigned to one of the four texture classes listed in Table 1. In the second step, soil hydraulic conductivity at a certain pressure head $h_{j}$ may be calculated from water content differences according to Eq. (1):

$$
\log _{10} K_{j}\left(h_{j}\right)=p_{0, j}+\sum_{i=1}^{4} p_{i, j} d_{i}+p_{5, j} d_{3, j}^{p_{6, j}}
$$

$j$ denotes one of the above mentioned pressure head values, $K$ is the hydraulic conductivity ( $\mathrm{cm} /$ day), $p$ is a parameter explained below and $d_{i}(i=1 \ldots 4)$ indicates the water content difference (percent by volume) given by:

$$
\begin{aligned}
& d_{1}=\theta(0)-\theta(32), \\
& d_{2}=\theta(32)-\theta(63), \\
& d_{3}=\theta(63)-\theta(316), \\
& d_{4}=\theta(316)-\theta(15850) .
\end{aligned}
$$

Table 1. Definition of four texture groups, equivalent particle diameters: clay: $\mathrm{d}<0.002 \mathrm{~mm}$, silt: $0.002<\mathrm{d}<0.06 \mathrm{~mm}$

\begin{tabular}{lll}
\hline No. & Texture class & Silt and clay contents \\
\hline 1 & Silt & $>65 \%$ silt with $<25 \%$ clay \\
2 & Loamy sand and & silt $<65 \%$, clay $<25 \%$ \\
3 & sandy loam & clay $>25 \%$ \\
4 & Sayd & silt $<10 \%$, clay $<5 \%$ \\
\hline
\end{tabular}

Thus, the CRC method offers a novel way to predict unsaturated soil hydraulic conductivity directly from soil water content without fitting a continuous model.

Tests have been performed to check the quality of the predicted $\left(\hat{y}_{i}\right) v s$. the measured hydraulic conductivity data $\left(y_{i}\right)$ by the root mean square error $(R M S E)$ :

$$
\text { RMSE }=\sqrt{\frac{\sum_{i=1}^{n}\left(y_{i}-\hat{y}_{i}\right)^{2}}{n}},
$$

by the coefficient of efficiency (COE, Legates and McCabe, 1999),

$$
C O E=1-\frac{\sum_{i}\left(y_{i}-\hat{y}_{i}\right)^{2}}{\sum_{i}\left(\widehat{y}_{i}-\hat{y}\right)^{2}},
$$

and by the Willmott index WM (Willmott et al., 2012), 


$$
W M=1-\frac{\sum_{i=1}\left(y_{i}-\widehat{y}_{i}\right)^{2}}{\sum_{i=1}\left(\left|\hat{y}_{i}-\dot{y}\right|+\left|y_{i}-\dot{y}\right|\right)^{2}} .
$$

As yet, the results provide nothing more than the values of the soil hydraulic conductivity at five selected pressure head points. Since most applications require the parameters of a continuous model, in a subsequent step the van Genuchten/Mualem model may be fitted simultaneously to the measured soil water content data and to the CRCgenerated values of hydraulic conductivity.

The well known van Genuchten (1980) relationship is defined by:

$$
\theta(h)=\theta_{r}+\frac{\theta_{s}-\theta_{r}}{\left(1+(\alpha h)^{n}\right)^{m}},
$$

$\theta$ - volumetric water content, $h$ - pressure head (assumed to be positive) $m=1-\frac{1}{n}$.

The figures $\theta_{s}, \theta_{r}, \alpha$ and $n$ denote free parameters and were fitted to the observed values of water content at $|h|=0$, $32,63,316$ and $15850 \mathrm{hPa}$.

From $S=\left(\theta-\theta_{r}\right) /\left(\theta_{s}-\theta_{r}\right)$, hydraulic conductivity $K(S)$ was calculated using Eq. (6):

and

$$
K_{r}(S)=S^{\tau}\left[1-\left(1-S^{1 / m}\right)^{m}\right]^{2}
$$

$$
K(S)=K_{0} K_{r} .
$$

The tortuosity parameter $\tau$ was set at 0.5 , and $K_{0}$ is a parameter which is commonly identified as the saturated hydraulic conductivity. Since the saturated hydraulic conductivity value was unknown, the observed hydraulic conductivity $K_{m p}$ at $h=-63 \mathrm{hPa}$ was chosen as a matching point, leading to an apparent value of $K_{0}$ given by:

$$
K_{0}=\frac{K_{m p}}{K_{r}\left(S_{m p}\right)},
$$

where: $K_{r}$ represents the relative hydraulic conductivity and $S_{m p}$ the saturation level at $h=-63 \mathrm{hPa}$.

Several researchers recommend using a matching point different from the saturation point. Vogel et al. (2001) has shown that even a shift from zero to $-2 \mathrm{~cm}$ can greatly improve hydraulic conductivity predictions. The research team used the measured value of hydraulic conductivity at $-63 \mathrm{hPa}$ as a matching point. Due to this necessary compromise, the prediction quality may be judged based on the four remaining pressure head values only.

Recently, Soto et al. (2017) described a fractal-based model of soil hydraulic functions.

Their water retention model is as follows:

$$
\theta(h)=\theta_{r}\left(1+\left(\frac{h}{h_{0}}\right)^{-\lambda}\right) \text { for } h>h_{a}
$$

and $\theta(h)=1 \quad$ for $0 \leq h \leq h_{a}$.
From the derivation of Eq. (9) it may be seen that $\lambda$ has a relationship with the fractal dimension $D$, which is given by $\lambda=3-D$. The parameter ha represents the observed or assumed bend of the water retention function indicating the air entry value and is given by:

$$
h_{a}=h_{0}\left(\frac{S_{r}}{1-S_{r}}\right)^{-\lambda} \text {. }
$$

In this equation, $S_{r}$ is given by $S_{r}=\theta_{r} / \theta_{s}$.

Soto et al. (2017) provided equations to calculate the function of hydraulic conductivity on the basis of the Burdine and Mualem theories. For the Mualem method, they obtained the following:

$$
\begin{array}{r}
K_{r}\left(S_{e}\right)=S_{e}^{\frac{19-5 D}{6-2 D}}, \\
\text { with } S_{e}=\frac{\theta-\theta_{r}}{\theta_{s}-\theta_{r}} .
\end{array}
$$

Thus, like the van Genuchten model, the fractal model has four fitting parameters. It is an advantage of this model that it is mathematically more easily accessible to the analytical solutions of flow equations than the van Genuchten/ Mualem model. The Soto model originates from fractal considerations. Although we are presently not aware of a reliable method to deduce the parameters of the fractal model directly from grain size distribution, it is conceivable that a relationship between grain size distribution and its parameters may be found in the future. That would produce new options for developing pedotransfer functions.

Weynants et al. (2008) used the database of Vereecken (1988) containing the data of 220 soil horizons mainly originating from Belgium to set up new pedotransfer functions which use textural data, bulk density and organic carbon content as input parameters. The functions not only provide the parameters of the van Genuchten function, but also the tortuosity coefficient and an apparent saturated hydraulic conductivity $K_{0}$ is also required to apply the Mualem function. $K_{0}$ acts as a matching point at suction head $h=0$ but it does not include the effect of macropores.

This PTF predicts the parameters of the van Genuchten water retention model from textural data and bulk density. Organic matter content was excluded from the calculations because they are often unavailable. The database used in this approach contained 676 soils mainly taken from two international databases. In order to predict hydraulic conductivity, the Mualem model (Eq. (3)) was used. To obtain the missing parameters $\tau$ and $K_{0}$, we followed the method described above.

\section{RESULTS}

The parameters $p_{1}$ through to $p_{6}$ of Eq. (1) to be used for the four texture classes and 5 pressure heads are given in Table 2. For clay soils they are merely based upon the results produced by 13 soils and should be taken as a preliminary approximation. The parameters listed in Table 2 
Table 2. Parameters of Eq. (1)

\begin{tabular}{|c|c|c|c|c|c|c|c|c|c|}
\hline $\begin{array}{l}\text { Texture } \\
\text { group }\end{array}$ & $\begin{array}{c}\text { Pressure } \\
\text { head } \\
(\mathrm{hPa})\end{array}$ & $j$ & $p_{0, j}$ & $p_{1, j}$ & $p_{2, j}$ & $p_{3, j}$ & $p_{4, j}$ & $p_{5, j}$ & $p_{6, j}$ \\
\hline \multirow{5}{*}{1} & 30 & 1 & -0.099891 & 0 & 0 & 0.064122 & 0 & -91.1321 & -4.3894 \\
\hline & 60 & 2 & 0.17261 & 0 & 0 & 0.02876 & 0 & -12.6949 & -2.00207 \\
\hline & 100 & 3 & 11.7745 & 0 & 0 & -0.321154 & 0 & -16.9630 & -0.29246 \\
\hline & 300 & 4 & -6.1720 & 0 & 0 & -0.367873 & 0.08383 & 2.377677 & 0.464374 \\
\hline & 600 & 5 & -5.4348 & 0 & 0 & -4.09279 & 0.05442 & 5.173351 & 0.92042 \\
\hline \multirow{5}{*}{2} & 30 & 1 & 0.297554 & 0.01903 & 0.024614 & 0 & 0 & -16.2345 & -2.02499 \\
\hline & 60 & 2 & 0.956675 & 0 & 0.022 & -0.01303 & 0 & -5.07067 & -0.74522 \\
\hline & 100 & 3 & 1.030225 & 0 & 0 & -0.02233 & 0 & -3.7443 & -0.40356 \\
\hline & 300 & 4 & -0.84804 & 0 & 0 & -0.07128 & 0.00078 & -2.16568 & -0.70757 \\
\hline & 600 & 5 & -1.58257 & 0 & 0 & 1.652779 & 0.00638 & -2.07409 & 0.927077 \\
\hline \multirow{5}{*}{3} & 30 & 1 & 14.5991 & -0.01184 & 0 & 2.573621 & 0 & -14.8624 & 0.393502 \\
\hline & 60 & 2 & 2.543126 & 0 & -0.19360 & 2.926924 & 0 & -5.65785 & 0.714309 \\
\hline & 100 & 3 & 7.28685 & 0 & -0.12988 & -0.15977 & 0 & -12.2582 & -0.28998 \\
\hline & 300 & 4 & 0.758729 & 0 & 0 & -0.385819 & 0.01154 & -26.5541 & -1.86899 \\
\hline & 600 & 5 & 0 & 0 & 0 & 0 & 0 & 0 & 0 \\
\hline \multirow{5}{*}{4} & 30 & 1 & -0.31134 & -0.02471 & 0 & 0.092958 & 0 & 0 & 0 \\
\hline & 60 & 2 & 61.86278 & 0 & 0.05293 & -0.2816 & 0 & -65.6632 & -0.03676 \\
\hline & 100 & 3 & -2.76471 & 0 & 0 & 0.190854 & 0 & 0 & 0 \\
\hline & 300 & 4 & 16.0555 & 0 & 0 & 0.305224 & 0.05917 & -19.20 & 0.051576 \\
\hline & 600 & 5 & 2.6666 & 0 & 0 & 0.126391 & 0.06536 & -7.33615 & 0.000108 \\
\hline
\end{tabular}

Table 3. Goodness of fit of hydraulic conductivity predictions of the CRC method, coefficients are derived from $\log 10 \mathrm{~K}\left(\mathrm{~cm} \mathrm{~d}^{-1}\right)$

\begin{tabular}{|c|c|c|c|c|c|c|c|c|}
\hline \multirow{2}{*}{$\begin{array}{l}\text { Pressure } \\
\text { head } \\
(\mathrm{hPa})\end{array}$} & \multicolumn{4}{|c|}{ No outlier selection } & \multicolumn{4}{|c|}{ Ooutlier selection $\mathrm{t}=3(\alpha=0.01)$} \\
\hline & $n$ & RMSE & Willmott & $C O E$ & $n$ & $R M S E$ & Willmott & $C O E$ \\
\hline 30 & 106 & 0.311 & 0.875 & 0.630 & 86 & 0.236 & 0.928 & 0.780 \\
\hline 60 & 106 & 0.258 & 0.913 & 0.729 & 85 & 0.173 & 0.960 & 0.855 \\
\hline 100 & 106 & 0.317 & 0.860 & 0.583 & 87 & 0.226 & 0.926 & 0.746 \\
\hline 300 & 106 & 0.391 & 0.780 & 0.418 & 93 & 0.269 & 0.881 & 0.619 \\
\hline 600 & 106 & 0.324 & 0.859 & 0.600 & 87 & 0.215 & 0.921 & 0.752 \\
\hline Mean & & 0.320 & & & & 0.224 & & \\
\hline
\end{tabular}

were estimated using the Levenberg-Marquardt method. The selection of the cause variables was performed iteratively and indicates a satisfactory performance of the CRC method.

In Table 3, the RMSE values are subdivided into different classes of pressure head. Compared to the first three levels, the predictions for 300 and $600 \mathrm{hPa}$ appear to be less reliable. Silty soils performed best and sandy soils worst. An overall view is given by Fig. 2 .

Interestingly, the results depend to a large extent on the treatment of outliers. Without the elimination of outliers, the average RMSE increases from 0.224 to $0.32 \log 10(K)$. The use of confidence limits for $\alpha=0.01$ corresponding to a $1 \%$ error probability in the case of a normal distribution reduces $R M S E$ greatly. There is a possibility that outliers are not only caused by random errors of measurement or by the bias of the model, but also by hidden soil properties. Without the elimination of outliers, the distribution of prediction errors shows a rapid increase at high score values. For this reason, the research team suspects that soil properties, not taken into account by the predictive equations, indirectly divide the soil samples into different subgroups. These unknown soil properties may be the tortuosity and the connectivity of the soil pore system or the presence of the bimodal shape of the water retention function. In this regard, no such information was available. The inclusion of bulk density or porosity into our predictions did not lead to substantial improvements. In practice, properties which 


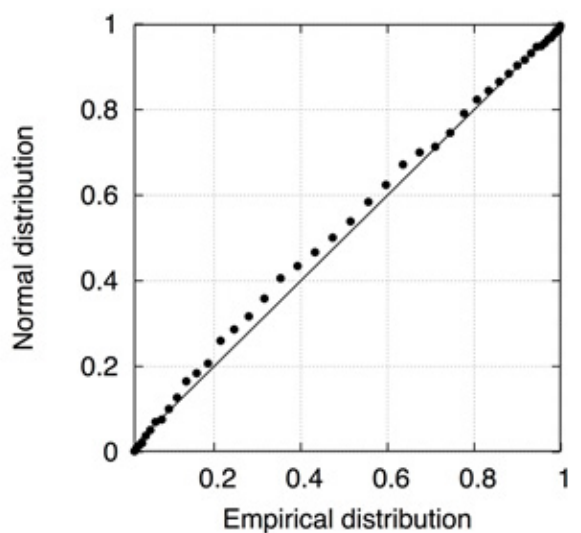

Fig. 2. CRC method, probability distribution of residuals.

CRC

(with outlier selection)

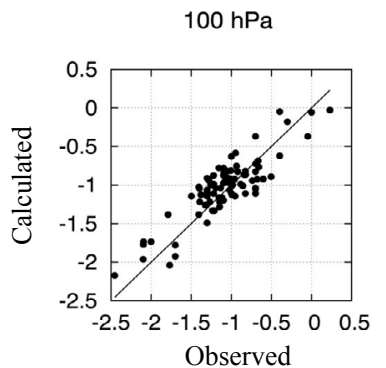

$30 \mathrm{hPa}$

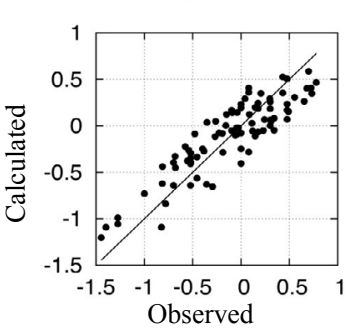

$63 \mathrm{hPa}$

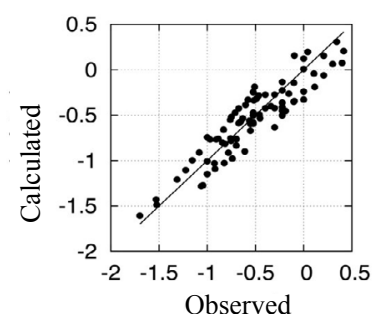

$300 \mathrm{hPa}$

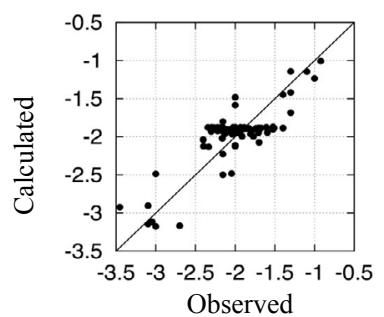

$600 \mathrm{hPa}$

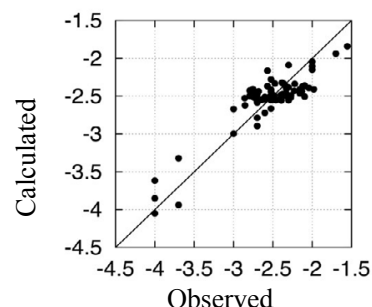

Fig. 3. Comparison between measured and predicted values of hydraulic conductivity, $\log (K), \mathrm{cm} \mathrm{d}^{-1}$, CRC-method.

exceed the texture data and bulk density are unknown as a general rule. For that reason, the application of PTFs must coexist with limited soil information. Despite this problem, the proposed method yields reliable results. Figure 3, which shows the probability distribution of residuals after the elimination of outliers at a $1 \%$ error level indicates that residuals are roughly normally distributed. The Kolmogoroff-Smirnov test does not reject the normal dis-

tribution assumption at the 5\% error level. Table 3 indicates a reliable prediction of soil hydraulic conductivity by the CRC method.

As mentioned above, most applications of pedotransfer functions require a knowledge of soil hydraulic parameters rather than discrete values of soil hydraulic conductivity. For that reason, we fitted the $\mathrm{MvG}$ model to measured water retention data and simultaneously to the PTF-generated hydraulic conductivity data. Comparing the model-calculated values of hydraulic conductivity to the measured values revealed an increase in RMSE from 0.224 as shown in Table 3 to 0.332 .

In the first step, the parameters of the MvG model were fitted to the soil water retention data. No more than five points of the WRC were available. Since this study compares the performance of various methods to predict soil hydraulic conductivity, similar levels of information should be used.

In order to locate the position of the global error minimum, in the first step, by following the Monte Carlo Method (MCM), 90000 random numbers of parameters were used. Based on these initial estimates, a Fibonacci parameter optimization was performed (Vardavas, 1989). The results of the MCM were only used as initial estimates. The following search algorithm had the full range of reliable parameters at its disposal. The average goodness of fit was $0.0103 \mathrm{~cm}^{3} \mathrm{~cm}^{-3}$ after the MCM-step and $0.0064 \mathrm{~cm}^{3} \mathrm{~cm}^{-3}$ after the Fibonacci search indicating on average a good representation of water retention by the model.

In order to calculate soil hydraulic conductivity (Eq. (3)), a matching point at $-63 \mathrm{hPa}$ was used. Since the observed value of hydraulic conductivity at $-63 \mathrm{hPa}$ was chosen, the results at this pressure head level do not represent a prediction. The prediction results are shown in Table 4.

Prediction errors are similar to those of the CRC method but were on average somewhat larger. Figure 4 indicates larger errors at $-600 \mathrm{hPa}$. In order to rank the method in comparison to the CRC method, we must consider two conflicting influences. The MvG method is in favour because much more information is provided to the MvG method than is used by the CRC method. On the other hand, the

Table 4. Goodness of fit of hydraulic conductivity predictions of the Mualem/van Genuchten method

\begin{tabular}{|c|c|c|c|c|c|c|}
\hline \multirow{2}{*}{$\begin{array}{c}h \\
(\mathrm{hPa})\end{array}$} & \multicolumn{3}{|c|}{ No outlier selection } & \multicolumn{3}{|c|}{$\begin{array}{l}\text { Outlier selection } \\
\mathrm{t}=3(\alpha=0.01)\end{array}$} \\
\hline & $n$ & $R M S E$ & Willm. & $n$ & $R M S E$ & Willm \\
\hline-30 & 106 & 0.333 & 0.896 & 77 & 0.215 & 0.945 \\
\hline-60 & 106 & 0. & 1. & 81 & 0 & 1. \\
\hline-100 & 106 & 0.212 & 0.955 & 89 & 0.15 & 0.979 \\
\hline-300 & 106 & 0.583 & 0.769 & 95 & 0.388 & 0.832 \\
\hline-600 & 106 & 0.729 & 0.715 & 96 & 0.479 & 0.778 \\
\hline Mean & & 0.464 & & & 0.308 & \\
\hline
\end{tabular}


$\mathrm{MvG}$

(with outlier selection)
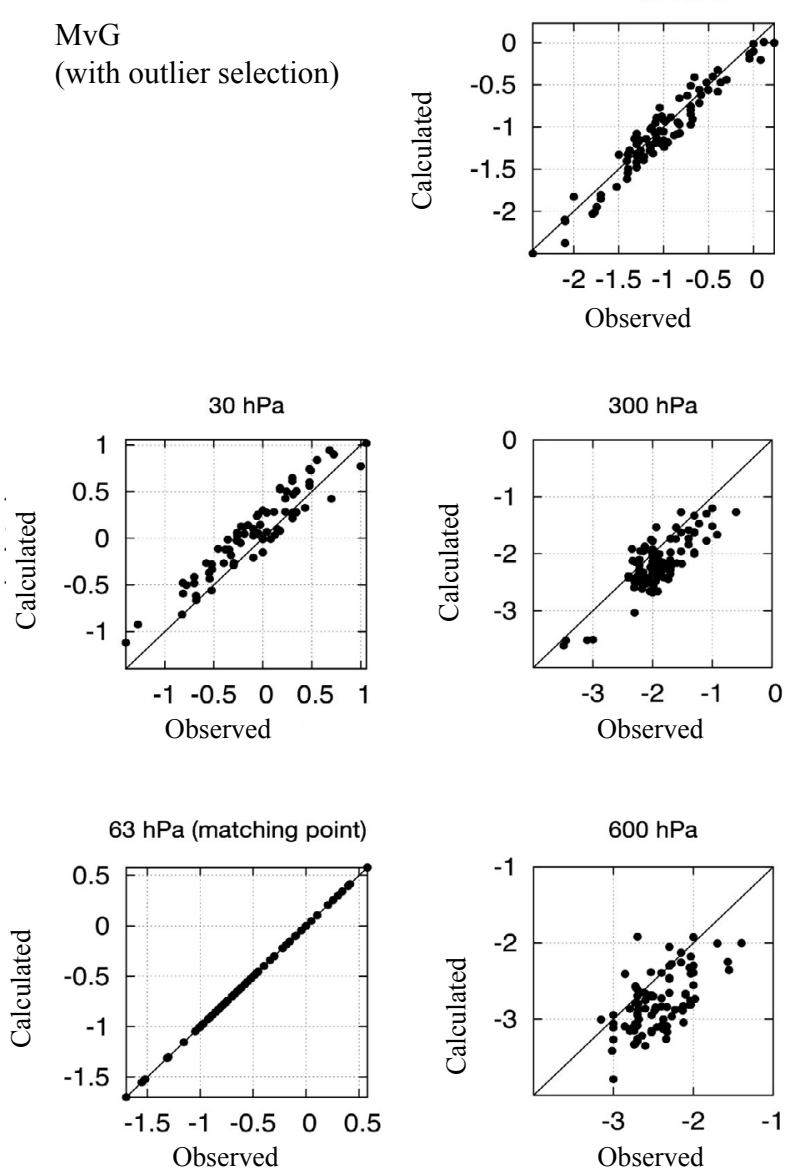

Fig. 4. Comparison between measured and predicted values of hydraulic conductivity, $\log (K), \mathrm{cm} \mathrm{d}^{-1}$, MvG method.

results of the CRC method are obtained by using the calibration data set, whereas the same data set is a validation data set for MvG. That is, the differences do not discriminate between the methods in themselves but between their suitability for application in practice.

The soil parameters of the fractal method proposed by Soto et al. (2017) were estimated from water retention data similar to the procedure outlined above. In this case, the surface of the water retention errors seems to be very irregular or ragged. An important requirement of the Fibonacci optimization technique is that there must be only one error minimum within the actual search range. Obviously, this requirement was not met when the parameter search was perfomed over a large range. The research team had to restrict the range and allowed the parameters to be estimated only in a narrow surrounding around the MCM results. The average RMSE was 0.0125 after performing the MCM search and $0.00998 \mathrm{~cm}^{3} \mathrm{~cm}^{-3}$ after the second step. Interestingly, this result is only slightly worse than that obtained with the van Genuchten model. Based on parameters estimated from soil water retention, the relative hydraulic conductivity was calculated by Eq. (7). With
Table 5. Goodness of fit of hydraulic conductivity predictions of the Soto fractal method

\begin{tabular}{ccccccccc}
\hline \multirow{2}{*}{$\begin{array}{c}h \\
(\mathrm{hPa})\end{array}$} & \multicolumn{3}{c}{ No outlier selection } & & \multicolumn{3}{c}{$\begin{array}{c}\text { Outlier selection } \\
\mathrm{t}=3(\alpha=0.01)\end{array}$} \\
\cline { 2 - 4 } \cline { 7 - 9 } & $n$ & RMSE & Willm. & & $n$ & $R M S E$ & Willm. \\
\hline-30 & 106 & 0.333 & 0.899 & & 89 & 0.240 & 0.947 \\
-60 & 106 & 0. & 1. & & 97 & 0. & 1. \\
-100 & 106 & 0.395 & 0.859 & & 71 & 0.235 & 0.957 \\
-300 & 106 & 0.956 & 0.572 & & 67 & 0.715 & 0.724 \\
-600 & 106 & 1.367 & 0.436 & & 61 & 1.076 & 0.580 \\
Mean & & 0.763 & & & 0.566 & \\
\hline
\end{tabular}

regard to the matching point we followed the same method as described above. The results shown by Table 5 indicate favourable RMSE values down to $-100 \mathrm{hPa}$.

The prediction of hydraulic conductivity at lower levels of pressure head is associated with larger errors. With our data set, the Soto method shows a tendency to overestimate hydraulic conductivity (Fig. 5).
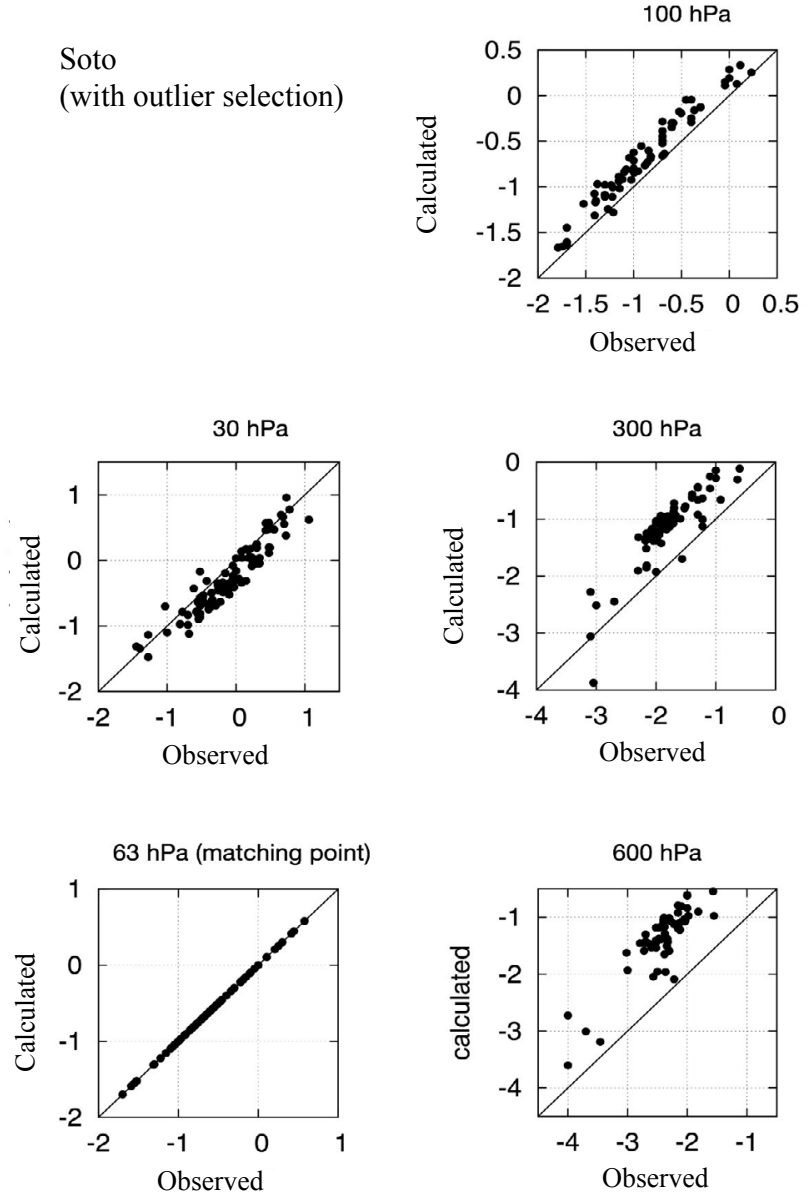

Fig. 5. Comparison between measured and predicted values of hydraulic conductivity $\log (K), \mathrm{cm} \mathrm{d}^{-1}$, fractal method. 
To complete the comparison between the new CRC method and various different methods, the pedotransfer functions (i) after Weynants et al. (2008) and (ii) after Zacharias and Wessolek (2007) were used to predict the hydraulic conductivity of the same set of soils. Both of them are based upon clay and silt content. Because the upper limit of silt is defined at $0.05 \mathrm{~mm}$ in contrast to $0.063 \mathrm{~mm}$ as used in our database, a logarithmic interpolation was performed. The Weynants method requires the organic carbon content to be known but this information was not available. Since the database used here contains mineral soils, an organic carbon content of $2 \mathrm{~g} \mathrm{~kg}^{-1}$ was assumed for all soils.

The Weynants method yields the water retention parameters of the van Genuchten model but also estimates of the tortuosity coefficient as well. Additionally, an estimate of the apparent hydraulic conductivity $K_{0}$ at zero suction is given, which does not include the effect of macroporosity.

In order to predict the hydraulic conductivity using the Zacharias PTF, the tortuosity parameter was assumed to be 0.5 and the matching point used was identified with the measured hydraulic conductivity at $-63 \mathrm{hPa}$.

Results indicate that both of the methods are reliable and perform well. Surprisingly, the Zacharias and Wessolek PTF yields an excellent predicition of the hydraulic conductivity at -30 and $-100 \mathrm{hPa}$ (Tables 6 and 7).

Table 6. Goodness of fit of hydraulic conductivity predictions of the pedotransfer function after Weynants et al. (2008) and Zacharias and Wessolek (2007). Outlier selection at the $1 \%$ error level

\begin{tabular}{ccccccccc}
\hline \multirow{2}{*}{$\begin{array}{c}h \\
(\mathrm{hPa})\end{array}$} & \multicolumn{3}{c}{ PTF Weynants et al. } & & \multicolumn{3}{c}{$\begin{array}{c}\text { PTF Zacharias } \\
\text { and Wessolek }\end{array}$} \\
\cline { 2 - 3 } \cline { 7 - 8 } & $n$ & RMSE & Willm. & & $n$ & RMSE & Willm. \\
\hline-30 & 87 & 0.454 & 0.455 & & 82 & 0.199 & 0.953 \\
-60 & 87 & 0.423 & 0.365 & & 88 & 0. & 1. \\
-100 & 88 & 0.333 & 0.322 & & 88 & 0.149 & 0.979 \\
-300 & 86 & 0.299 & 0.288 & & 89 & 0.412 & 0.855 \\
-600 & 91 & 0.307 & 0.425 & & 87 & 0.500 & 0.810 \\
Mean & & 0.362 & & & 0.315 & \\
\hline
\end{tabular}

Table 7. Concise summary of prediction errors in terms of RMSE

\begin{tabular}{lcl}
\hline Model & RMSE & Input data \\
\hline CRC & 0.320 & $\begin{array}{l}\text { water retention data } \\
\text { water retention data and PTF-generated } \\
\text { hydraulic conductivity }\end{array}$ \\
MvG & 0.332 & $\begin{array}{l}\text { water retention data, matching point } \\
\text { conductivity }\end{array}$ \\
Soto & 0.763 & $\begin{array}{l}\text { water retention data, matching point } \\
\text { conductivity } \\
\text { textural data, bulk density, organic } \\
\text { matter content } \\
\text { textural data, bulk density, matching } \\
\text { point conductivity }\end{array}$ \\
\hline
\end{tabular}

\section{DISCUSSION}

Information concerning soil hydraulic conductivity is required for many purposes, mainly for hydrologic land surface models to predict stream discharge and land flooding. In order to obtain relevant information, different methods have been proposed:

1. The measurement of soil hydraulic properties has been simplified by Peters and Durner (2008).

2. Several methods to predict soil hydraulic properties from soil texture and organic matter content have been developed (van Looy et al., 2017; Hewelke et al., 2015; Puhlmann and Wilpert, 2012; Woesten et al., 2001, among others). Most of these methods do not provide data concerning soil hydraulic conductivity, but rather they produce soil water retention data. Thus, a soil hydraulic model, for instance, the MvG model (Vogel et al., 2001) is required to obtain the soil hydraulic conductivity. In order to relate the non-hydraulic to the hydraulic soil properties, regression techniques and artificial neural network methods are used.

3. Databases such as UNSODA or HYPRES connected to neural networks codes are used (Schaap et al., 2001) and implemented into the common simulation models, such as HYDRUS.

Most pedotransfer functions are based on soil texture and provide soil hydraulic parameters. In contrast, the CRC method calculates the discrete values of hydraulic conductivity from water retention data. The dataset used in this study, is a training data set originating from typical soils in Germany and Austria. It was too small to be divided into a training and a validation data set. It must be left to the users to gather experiences concerning validations of their own. Moreover it is assumed, that the new CRC method as introduced here, is not intended for world-wide application but is likely to be useful for many landscapes in Europe. Based on our results, it is a reasonable possibility that there are important soil hydraulic properties which do not express themselves in data concerning soil texture and soil water retention. To mention just two, the tortuosity and connectivity of the pore system have a significant effect on soil hydraulic conductivity. These properties depend on geological materials and the age of the soils. Thus, they vary at a regional level and this circumstances may prohibit the world-wide application of only one set of pedotransfer functions.

\section{CONCLUSIONS}

1. Because pedotransfer functions are still influenced by the geological material of the training data set, climate and land use, pedotransfer functions users should control and validate the methods using own lab or field measurements.

2. We therefore suggest using the new CRC approach which only needs a few measured nodes of the water retention function to directly calculate the hydraulic conductivity at these points. 
3. If it becomes necessary to predict unsaturated soil hydraulic conductivity without any soil hydraulic information, the Weynants method is eligible. However, the most accurate prediction for unsaturated hydraulic conductivity is the pedotransfer functions of Zacharias and Wessolek.

Conflict of interest: The Authors do not declare conflict of interest.

\section{REFERENCES}

Feichtinger F., 1990. Feld-, Labor- und indirekte Methoden zur Bestimmung der kapillaren Leitfähigkeit. Mitt. Bundesanstalt für Kulturtechnik und Bodenwasserhaushalt.

Hewelke P., Gnatkowski T., Tyszka J., and Żakowicz S., 2015. Analysis of water retention capacity for selected forest soils in Poland. Pol. J. Environ. Stud., 24, No. 3, 1013-1019. https://doi.org/10.15244/pjoes/23259

Legates D.R. and McCabe G.J., 1999. Evaluating the use of "goodness-of-fit" measures in hydrologic and hydroclimatic model validation. Water Res. Res., 35(1), 233-241. https://doi.org/10.1029/1998wr900018

Minasny B., Montzka C., Padarian J., and Verhoef A., 2017. Pedotransfer functions in Earth system science: challenges and perspectives. Reviews of Geophysics, DOI:10.1002/2017RG000581

Peters A. and Durner W., 2008. Simplified evaporation method for determining soil hydraulic properties. J. Hydrol., 356, 147-162. https://doi.org/10.1016/j.jhydrol.2008.04.016

Puhlmann H. and von Wilpert K., 2012. Pedotransfer functions for water retention and unsaturated hydraulic conductivity of forest soils. J. Plant Nutrition Soil Sci., 175, 221-235. https://doi.org/10.1002/jpln.201100139

Renger M., Bohne K., and Wessolek G., 2014. Verfahren zur Berechnung der ungesättigten und gesättigten Wasserleitfähigkeit aus einfach zugänglichen Daten. Bodenökologie und Bodengenese, Heft 43, TU Berlin.

Renger M., Stoffregen H., Klocke J., Facklam M., Wessolek G., Roth C., and Plagge R., 1999. Ein autoregressives Verfahren zur Bestimmung der gesättigten und ungesättigten hydraulischen Leitfähigkeit. J. Plant Nutr. Soil Sci., 162, 123-130. https://doi.org/10.1002/(sici) 1522-2624 (199903)162:2<123::aid-jpln123>3.0.co;2-y

Schaap M.G., Leij F.J., and van Genuchten M.Th., 2001. Rosetta: a computer program for estimating soil hydraulic parameters with hierarchical pedotransfer functions. J. Hydrol., 251 163-176. https://doi.org/10.1016/s0022-1694(01)00466-8

Soto M.A.A., Chang H.K., and van Genuchten M.Th., 2017. Fractal-based models for the unsaturated soil hydraulic functions.Geoderma, 306, 144-151. https://doi.org/10.1016/j.geoderma.2017.07.019

Van Genuchten M.Th., 1980. A closed-form equation for predicting the hydraulic conductivity of unsaturated soils. Soil Sci. Soc. Am. J., 44, 892-898. https://doi.org/10.2136/sssaj 1980.03615995004400050002x

Van Looy K., Bouma J., Herbst M., Koestel J., Minasny B., Mishra U., Montzka C., et al., 2017. Pedotransfer functions in earth system science: Challenges and perspectives. Reviews of Geophysics, 55(4). https://doi.org/10.1002/2017rg000581

Vardavas I.M., 1989. A Fibonacci search technique for model parameter selection. Ecological Modelling, 48, 65-81, Amsterdam. https://doi.org/10.1016/0304-3800(89)90060-4

Vereecken H., 1988. Pedotransfer functions for the generation of hydraulicproperties for Belgian soils. Ph.D. Dissertation Katholieke Universiteit Leuven, Leuven, Belgium.

Vogel T., van Genuchten M.Th., and Cislerova M., 2001. Effect of the shape of the soil hydraulic functions near saturation on variably-saturated flow predictions. Advances in Water Res., 24, 133-144. https://doi.org/10.1016/s0309-1708(00)00037-3

Wendroth O. and Nielsen D.R., 1995. Land surface processes sampling the landscape and analyzing spatio-temporal patterns. Proceedings of a workshop. ZALF-Bericht no. 31, Müncheberg.

Weynants M., Vereecken H., and Javaux M., 2008. Revisiting vereecken pedotransfer functions: Introducing a closedform hydraulic model. Vadose Zone J., 8, 86-95. https://doi.org/10.2136/vzj2008.0062

Willmott C.J., Robeson S.M., and Matsuura K., 2012. A refined index of model performance. Int. J. Climatology, 32(13), 2088-2092. https://doi.org/10.1002/joc.2419

Woesten J.H.M., Pachepsky Y.A., and Rawls W.J., 2001. Pedotransfer functions: bridging the gap between available basic soil data and missing soil hydraulic characteristics. J. Hydrol., 251, 123-150. https://doi.org/10.1016/s0022-1694(01)00464-4

Wösten J.H.M., Lilly A., Nemes C., and Le Bas C., 1999. Development and use of a data base of hydraulic properties of European soils. Geoderma, 90, 169-185. https://doi.org/10.1016/s0016-7061(98)00132-3

Zacharias S. and Wessolek G., 2007. Excluding organic matter content from pedotransfer predictors of soil water retention. Soil Sci. Soc. Am. J., 71(1), 43-50. https://doi.org/10.2136/sssaj2006.0098 